\title{
PUBLIC TRANSPORT USERS' PREFERENCES AND WILLINGNESS TO PAY FOR A PUBLIC TRANSPORTATION MOBILE APP IN MADRID
}

\author{
Guillermo Velázquez \\ PhD Candidate, TRANSyT-UPM, Spain \\ Andrés Monzón
}

Chair, Transport Department, Universidad Politécnica de Madrid, Spain

\section{SUMMARY}

Today, smart cities are presented as a solution to achieve a more sustainable urban development while increasing the quality of life of its citizens through the use of new technologies (Neirotti, 2013). Smart Mobility is based on innovative and sustainable ways to provide transport for the inhabitants of cities, enhancing the use of fuels or vehicle propulsion systems that respect the environment, supported by technological tools and a proactive behaviour of citizenship (Neirotti, 2013). In urban mobility, the purpose of the Smart Cities is to develop flexible systems for real-time information to support decisionmaking in the use and management of different transport modes, generating a positive impact, saving users time and improving efficiency and quality of service.

In this context, several solution types are being introduced in the world's cities. They enable the improvement of the abovementioned factors acting on the demand side resulting in more efficient journeys for individual travelers, and improved satisfaction with the service. (Skelley et Al., 2013) with a lower level of investment than that of infrastructure deployment or an increase in the level of service. One of the most extended solutions is the use of mobile apps for providing the user with contextualized -static and real time- transport information.

The study is based on a survey carried out among users of public transport in Madrid under the European OPTICITES project of the 7th Research Framework Programme. The survey contained items on their transportation habits, their level of skills and technological capabilities, and their main expectations about the possibility of using a new application, the main desired capabilities and willingness to pay for use.

The study results show the preferences of users of public transport capacity, static, real-time search and in-app services for a multimodal real-time application and willingness to pay for this service, all analyzed by different Slicers users. The results also establish the basis for an estimate of the usefulness of these applications for users of public transport. 


\section{SMARTPHONE APPS FOR MULTIMODAL PUBLIC TRANSPORT}

\subsection{Multimodality in public transportation}

Urban mobility is changing rapidly. Complexity is rising with larger cities, multiple modes and new service models. Effectively exploiting the advantages of multimodality is one main challenge of modern urban transportation systems, it being reflected on the EU's objectives for transportation: obtaining sustainable and seamless transport systems.

Differences in density and infrastructure availability within urban areas, as well as changing circumstances and citizen needs make distinct transportation modes more efficient in different areas of the city, at different times and for different purposes. With multiple modes available the number of trips whose optimal solution is a multimodal chain increases. To provide door to door type mobility solutions only a multimodal mobility offer can compete with private vehicles in flexibility, convenience and cost.

Enhancing multimodal transport does not require significant restructuring of transport networks; instead it's more related with improving the availability of information and the perceived quality of the service (van Nes, 2002). With the triumph of customer-focused services, public transport operators are challenged to evolve towards the provision of integrated mobility; schemes where mobility is offered in a way that can balance demand without over-dimensioning the capacity of the transport system, providing greater information to the user, increasing resilience to incidents and making the integration of services reality, contributing to the goal of achieving a more livable city (Banister, 2008).

\subsection{Smart Mobility. Smartphone Apps.}

The term Smart City has become in recent times synonymous with extensive use of information technology cities, although a Smart City means much more than that (De Santis et al. 2014). Smart Mobility is one of the main dimensions that the concept integrates. With new models that the Smart vision brings like sharing schemes, flexible design of facilities and services, user centric service provision or open access to information in real time, being applied also to the urban mobility field.

Urban mobility can make the best use of information technologies to harvest and analyze large volumes of data in a structured and integrated way to improve mobility services, or many other services in the city. One of the main challenges to enhance multimodality, integration of modes both at the physical and at the information level, can be effectively addressed through the use of ICTs, and more particularly, on the user level, through the use of smartphone APPs. Technological innovations like real-time information and trip planners are proving essential to obtain the maximum benefit from multimodal scheme, as travelers can be unaware of viable modal alternatives. (Kenyon et al. 2002)

There are already outstanding examples in this initiatives such as fare integration between modes and operators carried out in London and Madrid, the wide offer of open data in 
Santander, Chicago or San Francisco, a route optimization APP in Vienna or private initiatives as Moovit, Citymapper or Waze.

\subsection{Public Transport Mobile Applications. Impact of real time information on travellers.}

In the academic literature there are several studies on the utility of travel time information systems with regard to travel time savings (Toledo and Beinhaker, 2006), as well as on the cost of travel time variability (Börjesson, Fosgerau and Karlström, 2008) and increased user satisfaction with the service (Dziekan and Kottenhoff, 2007). There is a proved positive impact of improved information of public transport networks on urban economy, mobility and environment as it results in more efficient journeys for individual travellers, and improved satisfaction with the service (Skelley et Al., 2013).

However some studies have shown that currently, information plays a minor role in modal choice when compared to that in journey planning and execution for a chosen mode (Kenyon et al. 2003), today individuals still have to make their travel decisions under uncertain circumstances with respect to the travel time; they are not able to predict the exact travel time or arrival time before starting their trips given a departure time (Zheng Li et Al, 2010); uncertainty that increases in the case of multimodal chains.

Mobile solutions appear as a new solution to tackle these problems, presenting travellers with a personalized set of modal options that can include soft aspects like comfort or convenience, which can be determinant to persuade a modal change (Kenyon et al. 2003).

The general increase in penetration rates of mobile devices in most cities, mainly smartphone devices, and even in underdeveloped economies, suggest that transport authorities have the opportunity to integrate their offer taking it to a multimodal level in an effective and cost efficient way. Public transportation agencies can play an active role by releasing high quality data, thoughtfully engaging with users and developers, and advocating for high quality, affordable mobile service options. (Moss et al 2011)

Many transport authorities have already done so, or enabled others to do it for them. Some examples of this are the apps developed by Transport for London, the Region Autonome des Transports Parisiens or Singapore on the public side, or the opening of data to the private sector that has developed apps in cities like San Francisco, Boston or London.

However, as some futuristic gurus predict (Gartner, Cisco, IDC), most of these solutions still haven't reached all the value that could be derived with regard to personalized travel assistants and mobility as a service offerings.

\subsection{Public transport users' requirements and willingness to pay for public transport apps.}

The design and implementation of this kind of solutions has been mainly empirical with few studies on user preferences for this solutions. More studies exist on the information required; some examples are the ones carried about traffic information needs for real time journey 
planning like the ones carried out by Chorus et al. (2007) or Zografos et al. (2010) and on multimodal traveller information systems by Moss et al (2011) or Kramers (2014) stating that much of the functionality is lacking in current solutions, if they should support societal goals like sustainability. In this regard some studies are being conducted to address how to encourage sustainable behaviour in user decision making, like the one carried out for a biking social app by Felix et al promoting the four E's model, Enable, Engage, Encourage, Exemplify (Felix et Al. 2013).

To identify main features demanded by the user, static information features or some basic real time ones, may hold a certain degree of correlation in the requirements for the already existent web ones. However some studies have been carried out for mobile solutions like the one of Schaffer et al. (2014) stating that the selection of features and personalization of app offerings for mobility should focus on specific user groups or app purpose and that future designs that improve the presentation of alternatives in the modal split of the routing proposal and functions related to utility need to be addressed. (Schaffer et al. 2014)

Regarding the user's expected utility and willingness to pay for transportation information several studies have been carried out. The information on user willingness to pay is useful as a way to measure utility and therefore, to evaluate the potential benefit derived from the implementation of projects. (Misham et al. 2007) Up to now Studies focused on the impact of implemented real time information systems like the studies carried by Watkins et al. 2011

Our study addresses this problems, by inferring which capabilities are the most necessary for the users in each of the main transit information fields: static information, real time information, visualization, search and in app-utilities. Also some information on which barriers are seen as the most problematic for the adoption of these solutions, (According to the literature Flexibility and Trust act as key elements with regard to UTIS acceptance. (Skelley et Al., 2013) has been analysed. Finally, a user segmentation approach has been taken to analyse willingness to pay by different user groups, which in the future can lead to modelling users utility and address the need personalized information offering for the users of multimodal chains. 


\section{METHODOLOGICAL PROCEDURE FOR THE ANALYSIS}

\subsection{Online survey methodology}

Several of the items contained in the survey were fixed with regard to the European project OPTICITIES, mainly Likert-scale type questions associated to the Theory of Planned Behaviour that states that attitudes toward behaviour, subjective norms, and perceived behavioural control, together shape an individual's behavioural intentions and behaviours (Ajzen, 1991). Further elements of the online survey and the survey methodology have been based on the practice of social research (Babbie, 2010).

A set of questions was designed addressed at observing the users characteristics in the areas of travel behaviour, technological skills and predisposition to adopt both new technological solutions in general and mobile apps in particular. Then a set of questions concerning the users preferences within a transportation mobile app were introduced, as well as questions relative to their willingness to pay for such an application.

In the months of February and March 2015, a data collection campaign was conducted in one of the main interchange stations of the city in coordination with the transport authority of Madrid.

\section{Figure 1. Location of Avenida de América interchange station}

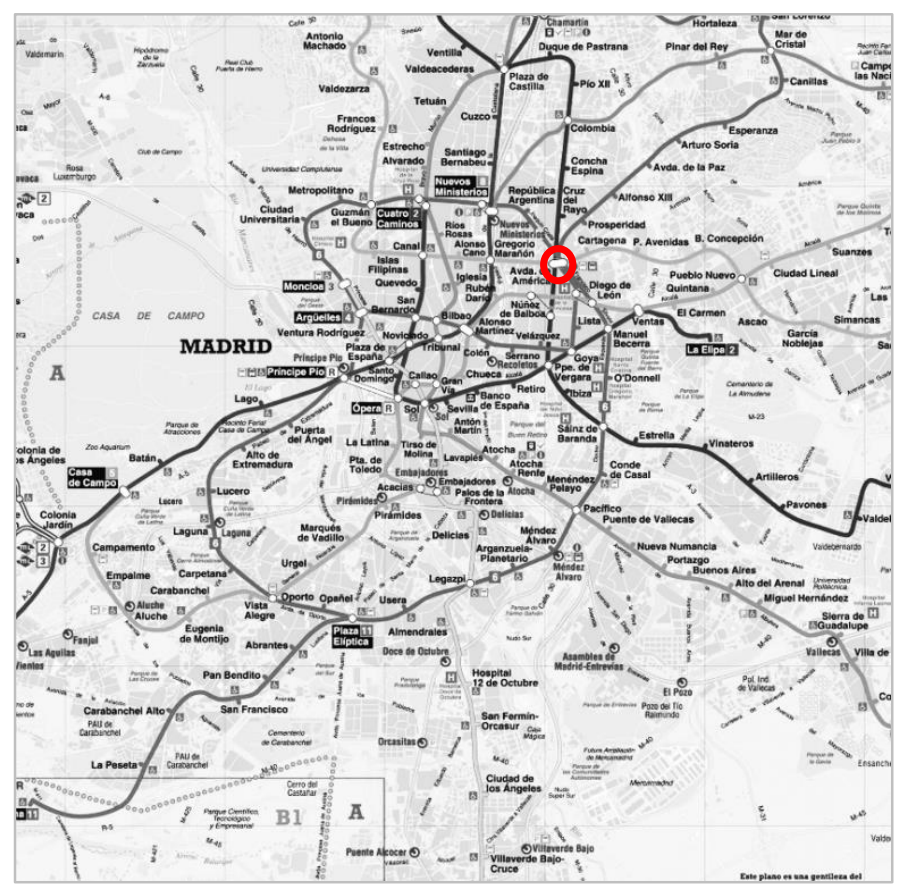

Figure 1 shows the location of the data collection site within the metropolitan area of Madrid. The station combines four subway lines (one ring line, three regular lines), eleven urban bus lines, and twelve inter-urban bus lines, as well as park and ride, with a demand of approximately 170.000 travellers per day. 


\subsection{Data Analysis.}

In order to analyze the collected information, first a descriptive analysis of the sample has been conducted in terms of sociodemographic characterization, travel behaviour and technological capabilities of the users.

Then a verification of the validity of the survey and of the representativeness of the sample with regard to Madrid's public transport user population has been conducted. A process of post stratification adjustment, used to adjust for sample weights so that the estimated joint distribution of a set of post stratifying variables matches the known population joint distribution (Chen et Al. 2012), was introduced to ensure non response from elderly travellers didn't bias the results of the study.

Travel behaviour description and most preferred features for the app: bar charts have been used to represent qualitative variables (Mode for the most frequent trip, Reason for most frequent trip, Frequency of most frequent trip,...) whilst histogram representations have been used for the quantitative ones (Age distribution, Average duration of most frequent trip,...).

Willingness to pay: a correlation analysis was conducted between theoretical percentages of time saved for the user's most frequent trip thanks to the app and the amount users were willing to pay for them. Given that both variables are ordinal type a Kendall's Tau b test was selected for the analysis. (Field, 2013).

Then, in order to analyse which population traits were relevant regarding the willingness to pay of the users, an analysis was conducted against the traits of gender, age, main mode for the most frequent trip, most frequent trip duration, educational level, income and smartphone use.

One-way ANOVA tests were carried out to examine whether there were statistically significant differences in willingness to pay among different user groups for each trait. Depending on the acceptance or rejection of the assumption of equal variances among groups, a Scheffe or Games-Howell post hoc test was used to verify where the difference lied.

\section{CASE STUDY: MADRID}

Madrid is a city of some 3.5 million inhabitants with its metropolitan area reaching 6 million. Three ring motorways surround the city: M-30, M-40 and M-50 and it has five fully operational (out of seven projected) multimodal interchange stations that connect the main accesses to the city with the public transportation network. According to the Household Mobility Survey of Madrid Region (CRTM, 2005, about 5 million displacements on public transport occur on a working day in the metropolitan area, which covers a developed area of $1,037 \mathrm{~km}^{2}$. This fact gives an idea of the importance of public urban transport management in a city with the size of Madrid. 
Madrid is making a great effort to improve its mobility by enhancing public transportation and multimodality, e.g. recently a public bicycle sharing system (BiciMAD) has been introduced in the central area of the city. With this aim, the transport authority has started to work on new solutions that exploit their operation data in order to improve the information services provided to the users and reduce the uncertainty of the user associated to disruptions in the service by unexpected incidents.

Following this line the transport authority has taken part in the European project OPTICITIES belonging to the $7^{\text {th }}$ Framework Program in which Madrid's main contribution is to emphasize urban experimentation in mobility fields like data processing, use of intensity of traffic data, integration of data related to vehicle traffic and pedestrian demands, analysing of public, scholar and worker transport focused on a better management for the city transit, experimentation on the functions and use of big urban commuting facilities already working in the city, etc.

\subsection{Sample characterization}

The survey involved a total of 200 women and 186 men, which represents almost equality in gender distribution within the sample. In terms of age, three groups were established: Young (18-30), adults (30 to 45 years) and senior travelers (50-70 years).

The most limiting group to be targeted in order to achieve a representative sample were senior travellers, as they are less adroit when it comes to the use of technology. In total 75 complete answers were obtained for this group. This set a percentage of senior travellers around $18 \%$, which isn't accurate with regard to the existent proportions in Madrid's population. Therefore a weighing of the sample to match the population age proportions has been carried out, in an attempt to reduce the impact of senior traveller population unit nonresponse (Little et Al. 2005) according to the population by age published on the last household survey published by the Spanish Statistical Office (2011).

\section{Figure 2. Population distribution for the selected intervals after adjustment}

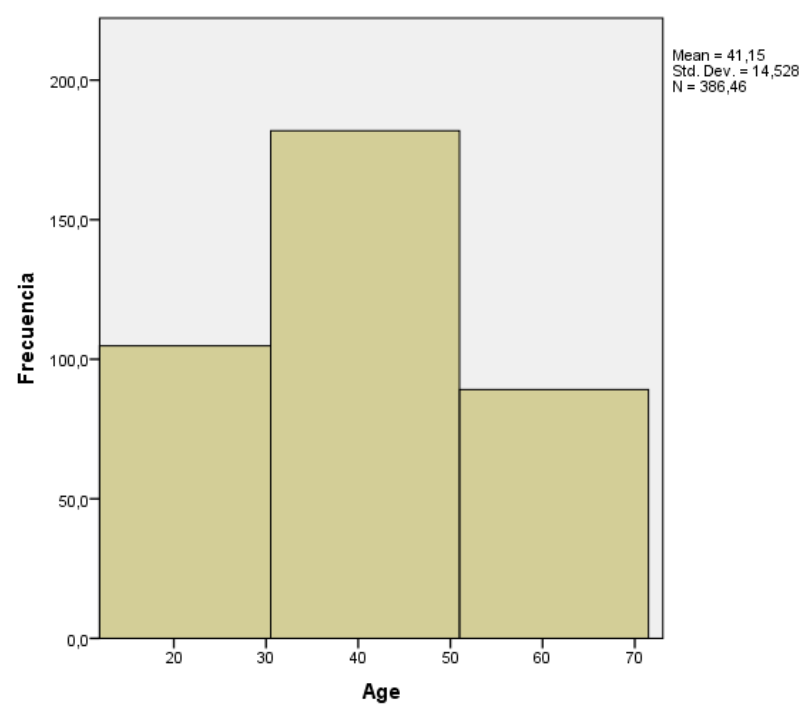


To analyze the travel behaviour of respondents they were presented a series of questions asking detailed information on their most frequent trip. The results showed a great weigh of intermodal trips characterizes the sample as expected with the combinations Bus-Subway and Subway-Bus accounting for more than $50 \%$ of multimodal trips.

\subsubsection{Technological capabilities}

In order to know the extent to which the users were comfortable with the use of different technological tools, they were asked about both their current device usage and their proficiency level in the use of each of the more broadly extended devices, even if they were not users of some of them.

The results are that technological penetration rates are high among Madrid's public transport users, with $\sim 78 \%$ of users being also users of personal computers and up to $86 \%$ stating a good level of proficiency in using them, and $\sim 84 \%$ of users being users of smartphones with the same rate stating a good or very good proficiency level on their use.

Income level of respondents was assessed as monthly income per household. The population was segmented into intervals of $€ 1,000$ income except the interval of 1000-2000€ monthly, which given its large volume was divided into two subsections of $500 €$ to ease comparability. The results are shown in Figure 3. It is noteworthy that one-third of respondents left this section blank.

\section{Figure 3. Histogram of income levels}

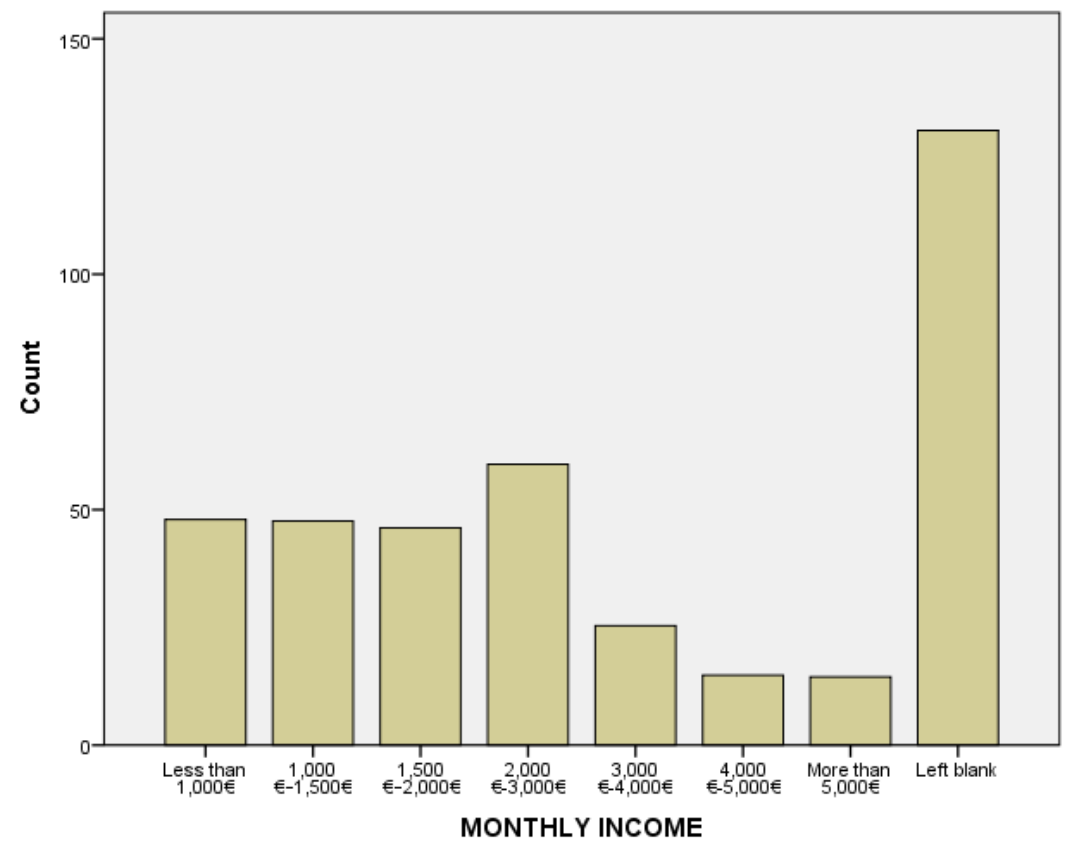




\section{RESULTS AND DISCUSSION}

First, the main results for preferences regarding App features and contents are explained, structured in the same way as in the survey: Static information features, real time information features, special event information features, search options, in-app services availability and App customization options.

Second, the main results for the analysis of the willingness to pay of the users, with the study of relevant differences among segmentations of the population according to gender, age, mode used for the most frequent trip, income, duration of most frequent trip and smartphone usage are included.

\subsection{APP features}

Users were queried on desired capabilities for the application. Several questions on desired features were raised in which the user had to rank capabilities either by selecting his or her three most desired capabilities or by ranking among a series of options split by static information, real time information, information regarding special events in the network and search options and other in-app services.

The main sets of information that users desire to receive through the app are:

\subsubsection{Static information}

Schedules and timetables of the different transportation modes (selected among the three most desired static information services by $70 \%$ of users), then routing information between any two points $(61 \%)$, visualizing a map with public transportation stops on it (41\%), checking information on an specific stop (address, stop number, etc.) (39\%) and being able to check graphically the itinerary of a line (37\%).

Figure 4. Most desired static information capabilities (\% of respondents selecting the option as their most desired, second most desired and third most desired)

\begin{tabular}{|l|c|c|c|c|}
\hline & 1 st & 2nd & 3rd & Total \\
\hline $\begin{array}{l}\text { Information about the schedules of public transport } \\
\text { services }\end{array}$ & $21 \%$ & $18 \%$ & $30 \%$ & $70 \%$ \\
\hline $\begin{array}{l}\text { Planning my trip from any origin to any destination } \\
\text { (regardless of my position) }\end{array}$ & $27 \%$ & $16 \%$ & $19 \%$ & $61 \%$ \\
\hline Viewing a map of the city & $21 \%$ & $8 \%$ & $12 \%$ & $41 \%$ \\
\hline Viewing public transport stops on a map & $9 \%$ & $19 \%$ & $12 \%$ & $39 \%$ \\
\hline $\begin{array}{l}\text { Basic information of public transport stops (street } \\
\text { adress, stop code, etc.) }\end{array}$ & $11 \%$ & $18 \%$ & $9 \%$ & $39 \%$ \\
\hline $\begin{array}{l}\text { Graphically displaying the itinerary of public } \\
\text { transport lines }\end{array}$ & $3 \%$ & $5 \%$ & $4 \%$ & $13 \%$ \\
\hline Maps of specific stops / transit stations & $100 \%$ & $100 \%$ & $100 \%$ & $300 \%$ \\
\hline Total & $8 \%$ & $13 \%$ & $37 \%$ \\
\hline
\end{tabular}

* Other options were visualizing the map of any station, and visualizing a general map of the city 


\subsubsection{Real time information}

Checking information on the closest public transportation stops in real time (selected among the three most desired real time information services by $87 \%$ of users), routing information from the users real time location $(74 \%)$, visualizing in real time the closest public transportation lines $(69 \%)$, real time information on the closest public transportation services $(65 \%)$, visualization of the user location on the map (59\%).

\subsubsection{Special events information}

Suggestions of public transportation alternatives when the user is planning his route (selected among the three most desired services related to events by $66 \%$ of users), information on lines and stops affected by the event (62\%), alternative route suggestions when the user is affected by an event (54\%), real time information on events that may affect the user's trip $(50 \%)$.

\subsubsection{Search options}

Users want the application to let them filter by closest stop (important or very important for $80 \%$ of users), filter by closest stop of a given transportation mode (ex. Bus) (79\%), filter by public transport stop name (73\%), search by closest stop of a given line (74\%) and, with less significance, search by public transportation stop code (49\%).

\subsubsection{In-app services}

Information on the user's transportation card: balance, recharge points and card information points were selected among the three most desired services by $63 \%$ of users. Guidance information: The main desired means to receive guidance information are plain map indications, arrow movement through a map, or through panoramic image strings, being considered as more important than camera visualization or radar indications. Payments through the app: selected among the three most desired services by $37 \%$ of users. Point Of Interest (POI) information: selected among the three most desired services by $27 \%$ of users.

\subsubsection{App customization}

The main desired features were: saving favourite stops and lines (73\% of users selected it among their three most desirable features), activating alerts on events affecting any of the user's favourite stops/lines (70\%), and personalized information on trip optimization $(55 \%)$.The possibility of changing the appearance of the app (colours, theme, font size, etc.) was desired by more than $50 \%$ of the surveyed users, and considered as not necessary by $24 \%$ of them. 


\subsection{Willingness to pay}

Considering all cases surveyed, a correlation analysis between time and price variables has been run. Figure 5 shows a linear construct with the average amounts users are willing to pay monthly for each percentage of time saved in their most frequent trip thanks to the use of the app.

\section{Figure 5. Willingness to pay for \% of time saved}

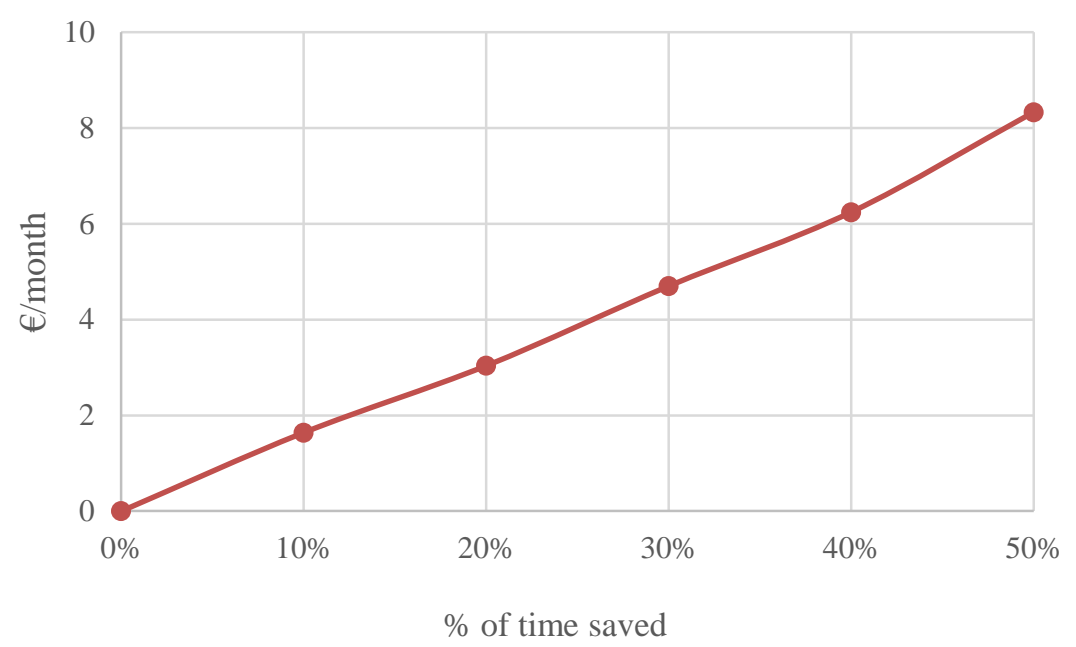

The results of the Kendall's Tau b test are brought here directly from SPSS. It is noteworthy that the number of cases is much larger than the initial sample as each respondent answered five different items containing their willingness to pay for each different amount of time saved.

The result of the test shows that as expected there is some degree of correlation among time savings and willingness to pay for the use of the app for the general population with a value of $\tau=0,351$ and a significance of the result of 0,000 .

Sig. is the probability that the relationship obtained could have occurred by chance, and is interpreted as follows:

Less than .01 - Highly significant

Between .01 and .05 - Moderately significant

Between .05 and .10 - Somewhat significant

Above .10 - Not significant

However the correlation is not very strong, therefore we assume that there must be different population segments in which the willingness to pay is both greater and can be modelled in a more precise way. Hence, as a second step and in order to analyse which population traits were relevant regarding the willingness to pay of the users, an analysis by each of the main traits within the population has been conducted.

For each of the sample segmentations we have displayed a figure showing the average amounts that the user groups in it are willing to pay for savings of time thanks to the use of the app. 


\subsubsection{Gender}

An analysis taking the gender variable as grouping factor was carried out. The two groups within the population are Men (48\% of the sample) and Women (52\% of the sample). The independent variable is the different percentages of time saved, whilst the dependent variable is the amount the users are willing to pay for each of those savings of time. The average values of the dependent variable are presented below split by population group.

\section{Figure 6. Willingness to pay for time saved, by gender group}

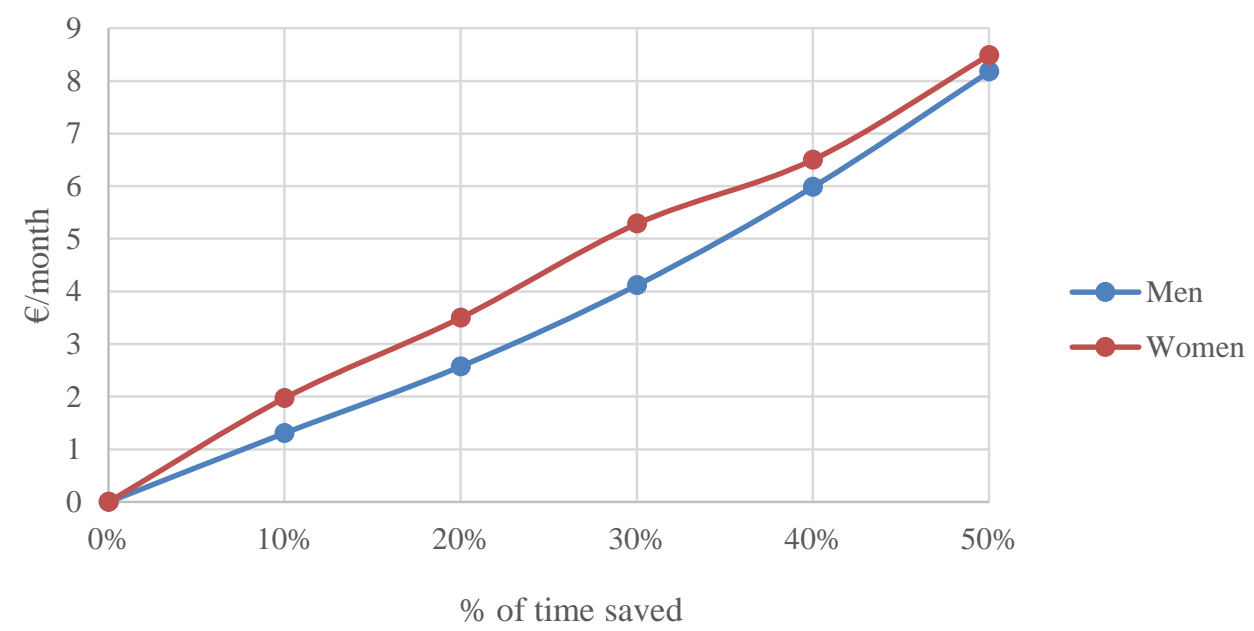

A one-way ANOVA test has been conducted to examine whether there were statistically significant differences among the different user groups' willingness to pay. Post hoc tests are not necessary in this case as the segmenting variable has only two groups.

The results reveal equal variances assumption is rejected for $10 \%, 20 \%$ and $30 \%$ time savings with $\mathrm{F}(1,345))=3,906$, p-value of 0,001 for $10 \%$ savings, $\mathrm{F}(1,347)=4,382$, p-value of 0,037 for $20 \%$ savings and $F(1,343))=6,074$, p-value of 0,014 for $30 \%$ savings. The assumption is met for $40 \%$ and $50 \%$ levels with $\mathrm{F}(1,337)=2,584$ and $\mathrm{F}(1,336)=1,065$ and p-values of 0,109 and 0,303 respectively. Differences in the sample size for each option are due to respondents selecting "I don't know" in some of the items.

The results revealed statistically significant differences among both groups for the lower tier of the time savings, which implies that in the studied sample men were less willing to pay than women for small percentage savings of time thanks to the use of the app. Differences in willingness to pay among the two groups for the higher end of time saving were found to be not significant.

\subsubsection{Age group}

An analysis taking the age group variable as grouping factor was carried out. The three groups within the population are young, comprising population aged between 15 and 30 (28\% of the sample), Adults, comprising population aged between 31 and 50 (48\% of the sample) and Senior, comprising population aged between 51 and 70 (23\% of the sample). Again the independent variable is the different percentages of time saved, whilst the 
dependent variable is the amount the users are willing to pay for each of those savings of time on their most frequent trip. The average values of the dependent variable are presented in figure 7 below split by population group.

\section{Figure 7. Willingness to pay for time saved, by age group.}

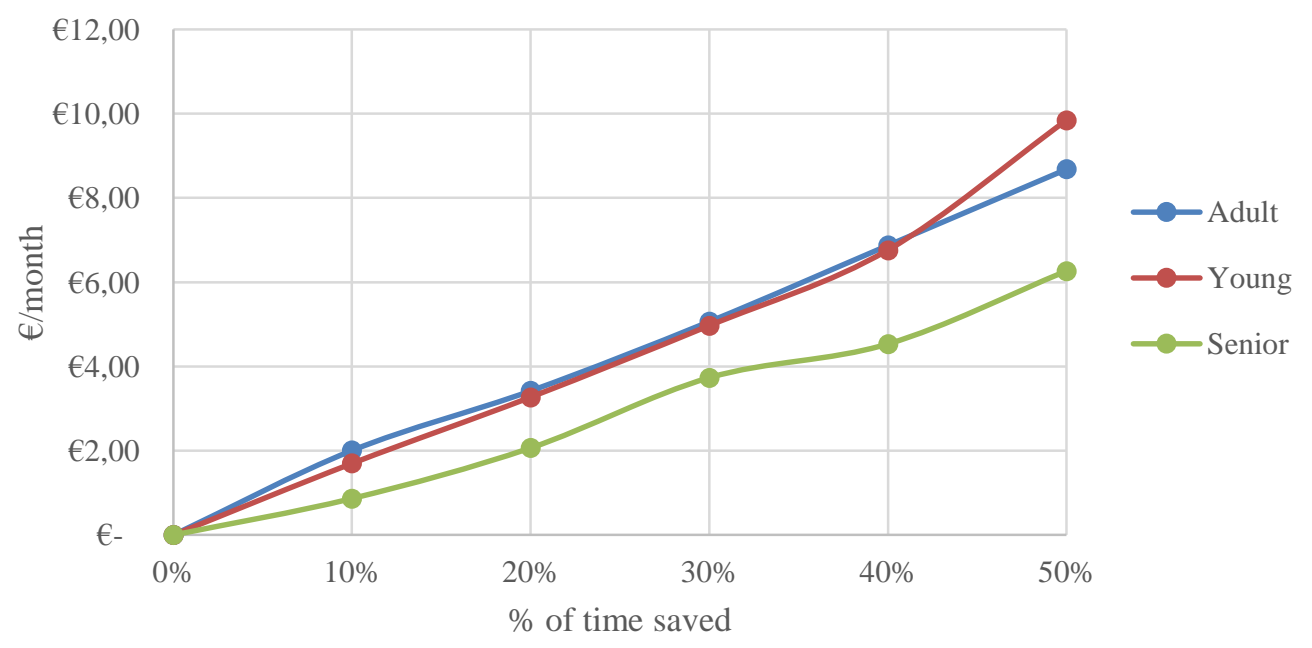

A one-way ANOVA test has been conducted to examine whether there were statistically significant differences among the three different user groups' willingness to pay.

The results reveal equal variances assumption is rejected for $50 \%$ time savings with $\mathrm{F}(2$, $334))=3,453$, p-value of 0,033 . For $40 \%$ savings and $10 \%, F(1,336)=2,864$, $p$-value $=0,061$ and $\mathrm{F}(2,345))=2,483$, p-value $=0,075$, which is above the standard 0,05 limit, but yet quite close meaning that there is some signinficant disparity in the means of the different groups. The assumption is met for $20 \%$ and $30 \%$ levels with $\mathrm{F}(2,345)=1,791$ and $\mathrm{F}(2,343)=, 719$ and $\mathrm{p}$-values of 0,168 and 0,488 respectively.

In order to statistically address which groups held the differences that the indicator had pointed out, post-hoc analysis were ran. First Levene's statistic was calculated for all of them. Then, depending on the statistic result the Games Howell test was analyzed for Sig. in Levene's $<0,05$, and the Scheffe test was analyzed for Sig. in Levene's test $>0,05$.

Games-Howell test was used for $10 \%$ and $40 \%$ time savings, as Sig. in Levene's test $<0,05$, while Scheffe test was used for $50 \%$ time, with Sig $=0,086$ (Table 14.).

Post-hoc tests revealed statistically significant differences between Senior travellers and Adult travellers and Young travellers. Young and Adult segments of the sample reported significantly higher willingness to pay for time savings thanks to the transportation app. There were no significant differences between the young and adult groups

\subsubsection{By main mode}

An analysis taking the variable mode used for the most frequent trip as grouping factor was carried out. The four categories with enough representativeness within the population are multimodal, bus only, car only as driver and subway only. Again the independent variable is the different percentages of time saved, whilst the dependent variable is the amount the 
users are willing to pay for each of those savings of time on their most frequent trip. The average values of the dependent variable are presented on the figure below split by population group.

\section{Figure 8. Willingness to pay for time saved, by mode used for most frequent trip.}

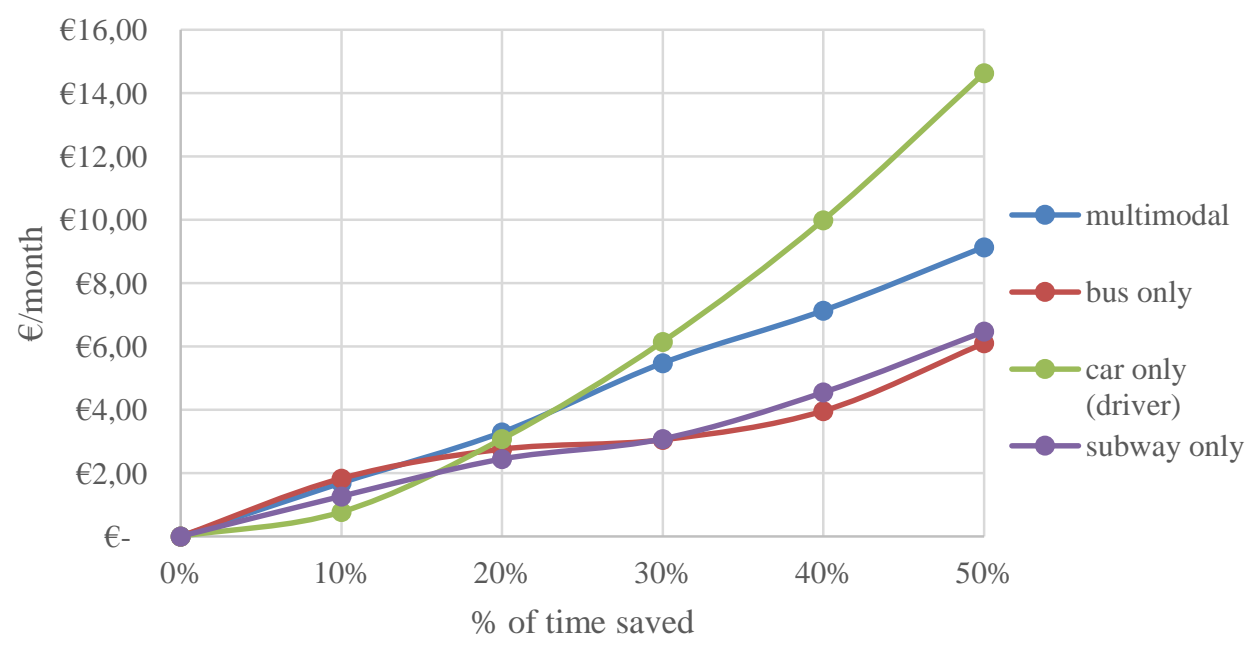

A one-way ANOVA test has been conducted to examine whether there were statistically significant differences among the different user groups willingness to pay.

The results reveal equal variances assumption is rejected for $30 \%, 40 \%$ and $50 \%$ time savings with $\mathrm{F}(3,322))=4,048$, p-value of 0,008 for $30 \%$ savings, $\mathrm{F}(3,317)=5,090$, p-value of 0,002 for $40 \%$ savings and $\mathrm{F}(3,316))=5,211$, p-value of 0,002 for $50 \%$ savings. The assumption is met for $10 \%$ and $20 \%$ levels with $\mathrm{F}(3,326)=0,569$ and $\mathrm{F}(3,324)=0,593$ and p-values of 0,636 and 0,620 respectively. Differences in the sample size for each option are due to respondents selecting "I don't know" in some of the items.

In order to statistically address which groups held the differences that the indicator had pointed out, post-hoc analysis were ran. First Levene's statistic was calculated for all of them. Then, depending on the statistic result the Games Howell test was analyzed for Sig. in Levene's $<0,05$, and the Scheffe test was analyzed for Sig. in Levene's test $>0,05$.

Games-Howell test was used for $40 \%$ time saving, as Sig. in Levene's test $<0,05$, while Scheffe test was used for $30 \%$ and 50\% timesavings, with Sig $=0,199$ and 0,207 respectively. (Table 18).

Post-hoc tests revealed statistically significant differences between Subway travellers and Multimodal and car as a driver travellers. Car and Multimodal segments of the sample reported significantly higher willingness to pay for time savings thanks to the transportation app. There were no significant differences between the other group combinations.

\subsubsection{Income group}

An analysis taking the income variable as grouping factor was carried out. Again the independent variable is the different percentages of time saved, whilst the dependent variable 
is the amount the users are willing to pay for each of those savings of time on their most frequent trip. The average values of the dependent variable are presented on the figure below split by population group.

\section{Figure 9. Willingness to pay for time saved, by income level.}

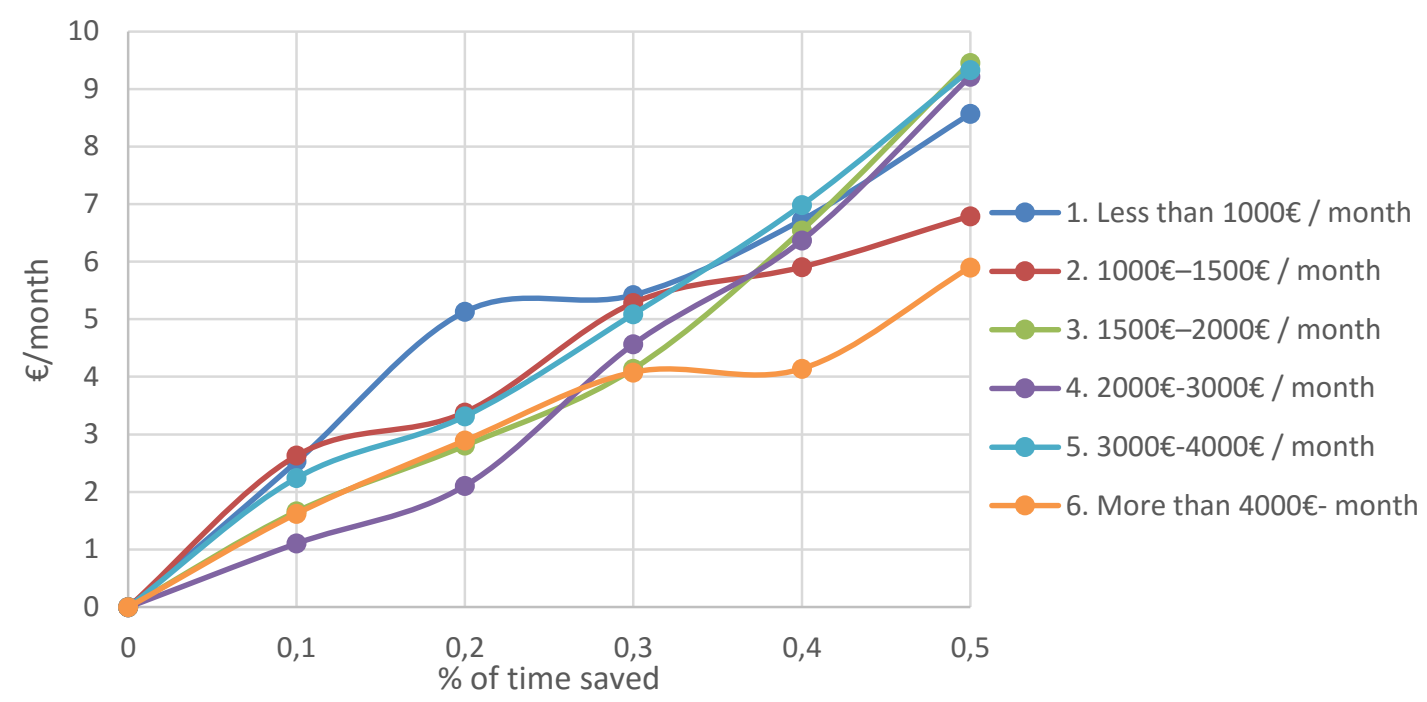

A one-way ANOVA test has been conducted to examine whether there were statistically significant differences among the different user groups willingness to pay.

The results reveal equal variances assumption is accepted for all time savings with significance levels of the result above the standard 0,05 limit, although for the $20 \%$ saving variable $\mathrm{Sig}=0,055$ indicating that there is some significant disparity in the means of the different groups. Hence we can conclude for this section that there is no statistically significant difference in willingness to pay for different income level groups.

\subsubsection{Duration of most frequent trip}

Figure 10. Willingness to pay for time saved, by duration of their most frequent trip.

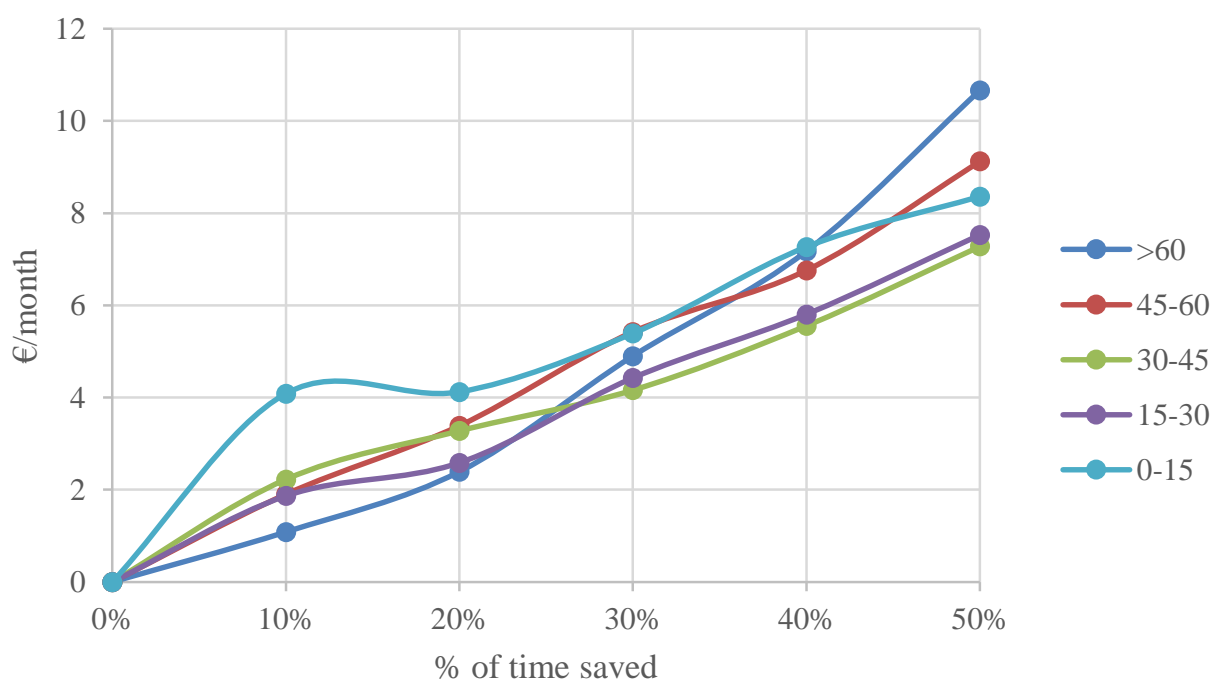


A one-way ANOVA test has been conducted to examine whether there were statistically significant differences among the different user groups willingness to pay.

The results reveal equal variances assumption is accepted for all time savings with significance levels of the results above the standard 0,05 limit for all of the variables. Hence we can conclude for this section that there is no statistically significant difference in willingness to pay for different income level groups.

\subsubsection{Smartphone use}

According to Table 5. 84\% of PT users in Madrid are users of smartphones with the same rate stating a good or very good proficiency level on their use.

\section{Figure 11. Willingness to pay for time saved, by Smartphone use.}

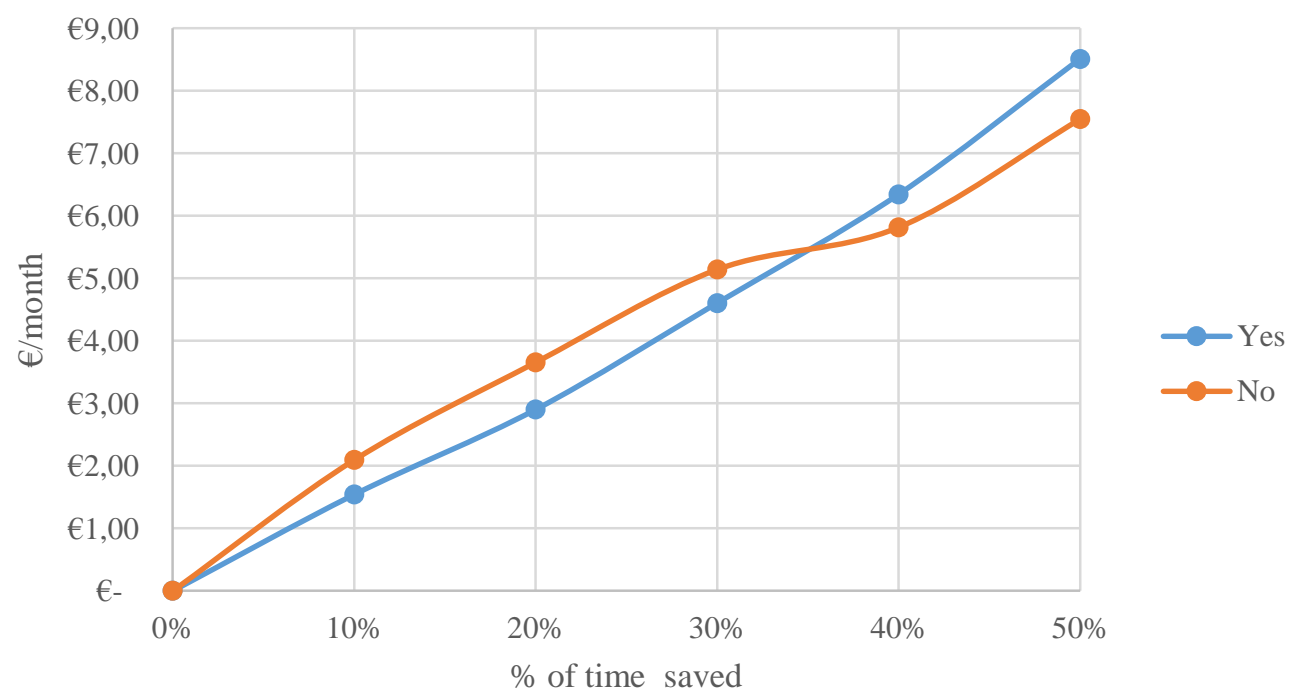

A one-way ANOVA test has been conducted to examine whether there were statistically significant differences among the different user groups' willingness to pay. Post hoc tests are not necessary in this case as the segmenting variable has only two groups.

The results reveal equal variances assumption is rejected for $20 \%$ time savings with $\mathrm{F}(1$, $345))=2,927$, p-value of 0,048 . For $10 \%$ savings $F(1,346)=2,678$, p-value $=0,068$ which is above the standard 0,05 limit, but yet quite close meaning that there is some significant disparity in the means of the different groups. The assumption is met for $20 \%, 40 \%$ and $50 \%$ levels with $\mathrm{F}(1,343)=2,362, \mathrm{~F}(1,338)=, 034$ and $\mathrm{F}(1,336)=0,156$ and $\mathrm{p}$-values of 0,125 , 0,854 and 0,693 respectively. Differences in the sample size for each option are due to respondents selecting "I don't know" in some of the items.

The results revealed statistically significant differences among both groups for the lower tier of the time savings, which implies that in the studied sample Smartphone users were less willing to pay than non-users for small percentage savings of time thanks to the use of the app. Differences in willingness to pay among the two groups for the higher end of time saving were found to be not statistically significant. 


\section{CONCLUSIONS}

On tool capabilities and design, the following conclusions can be drawn:

- Having a user friendly interface is essential as well as granting that the perception of the user is not for the app being too complex, or many of the potential users will not go through the necessary learning process.

- Inclusion of multiple options of filtering and searching for information, as users differ in preferences.

- Inclusion of multiple options of visualization of results, and for guidance information as users differ in preferences.

- Offering personalization features in order to improve the efficiency in its use and the overall user experience.

- Offering payment and subscription-related in-app services, as public transport card office information or mobile payment options.

- Ensuring that the services offered cover the most desired ones in each of the fields (static information, real time information and special events information).

- Offering the app for free, as most of the users are not willing to pay for the service.

Most users are interested in testing the app (77\% interested or very interested), and complexity in the daily use of the application or a not user-friendly interface are seen as the main barriers for its adoption.

As a first conclusion in the part of the study related to willingness to pay of the users it has been shown that there is a certain correlation between the user's expected time savings thanks to the use of a mobile app for public transportation and the willingness to pay of the users for it. However, as seen in the literature other factors that the app can improve apart from time saving can also generate utility for the user.

With regard to population segmentations the analysis has shown that gender and smartphone use have some degree of relevance in the willingness to pay of the users. With women and non-Smartphone users showing a higher predisposition to pay, that is, they expect higher utility from such a service than men or Smartphone users. As expected multimodality is directly correlated with the users' willingness to pay. When maintaining other variables constant the average amount that users are willing to pay for the app, in all the different timesaving options is greater for multimodal users, which has been proven statistically relevant. This means multimodal users find the greatest utility in this kind of applications. The results show the same trend for private car drivers, although the smaller representation of this segment in the sample calls for caution when interpreting the validity of this result.

Segmentations by income level and average length of the most frequent trip had no statistical significance regarding different willingness to pay of the members of different groups. 
The results of the research show that having to pay for the app is a great barrier, as $70 \%$ of the users are not willing to pay for the service, $13 \%$ would be willing to pay only at download time, $8 \%$ would only pay for premium services and only $5 \%$ would pay on a monthly basis.

\section{ACKNOWLEDGEMENTS}

This work stems from research carried out for OPTICITIES project addressed towards enhancing smart mobility in Europe and funded by the European Commission under R\&D EU's 7th Framework Program. The authors also acknowledge the collaboration of Madrid's transport authority (CRTM).

\section{REFERENCES}

Ajzen I., (1991). The theory of planned Behaviour. Organizational Behavior and Human Decision Processes.

Babbie R., (2010). The Practice of Social Research. Belmont: Wadsworth, Cengage Learning.

Börjesson, M., Fosgerau, M., Algers, S., (2008). The income elasticity of the value of travel time is not one number, Proceedings of the European Transport. Conference, Leiden, Netherlands.

Chen, Q., Gelman A., Tracy M., Norris F., Galea S., (2012). Weighting Adjustments for Panel Nonresponse. University of Columbia.

Chorus, C.G., Arentze, T.A., Timmermans J.P., (2007) Travelers' need for information in traffic and transit: results from a web survey. J. of Intelligent transport systems, 11 (2) (2007), pp. 57-67

CRTM (2005). Encuesta domiciliaria de movilidad 2004 en la Comunidad de Madrid. Retrieved from: http://prueba.crtm.es/media/157705/edm_2004.pdf. (Accessed May, 10, 2015).

Dziekan, K., Kottenhoff, K. (2007). Dynamic at-stop real-time information displays for public transport: effects on customers. Transportation Research part A.

Felix, C., Gay, V., Golliard, L., Johnston, B., Leijdekkers, P., Vaughan, E., Wang, X., Williams, M., (2013). What Can a Mobile App Do To Encourage Cycling?. Second IEEE International Workshop on Global Trends in Smart Cities 2013

Field, A., (2014). Discovering statistics using SPSS.

Kenyon, S., Lyons, G., (2003). The value of integrated multimodal traveller information and its potential contribution to modal change. Transportation research part $\mathrm{F}$.

Kramers, A., (2014). Designing next generation multimodal traveler information systems to support sustainability-oriented decisions. Environmental Modelling \& Software 
Volume 56, June 2014, Pages 83-93.

Little, RJ., Vartivarian S. (2005). Does Weighing for non response increase the variance of survey means?. Survey Methodology. 31:161-168

Mishan, EJ., Quah, E., (2007). Cost-benefit analysis

Moss M., Mandell J., Qing C., (2011). MOBILE Communications and TRANSPORTATION in Metropolitan Regions The Rudin Center for Transportation Policy and Management

Neirotti, P. (2012) Current trends in Smart City initiatives: Some stylised facts. Cities 38 (2014) 25-36.

Toledo, T., Beinhaker, R. (2006). Evaluation of the potential benefits of advanced traveller information system. Journal of of Intelligent Transportation Systems.

Santis, R., Fasano, A., Mignolli N., Villa A., Smart City: the future city? economia\&lavoro 1 (2014): 177-193.

Skelley, T., Namoun, A., Mehandjiev N., (2013) The Impact of a Mobile Information System on Changing Travel Behaviour and Improving Travel Experience.

Van Nes, R., (2002) Design of multimodal transport networks. A hierarchical approach. TRAIL Thesis Series, Delft University Press, The Netherlands

Watkins, K. E., Ferris, B., Borning, A., Rutherford, G. S., \& Layton, D. (2011). Where Is My Bus? Impact of mobile real-time information on the perceived andactual wait time of transit riders. Transportation Research Part A: Policy and Practice.

Zheng Li David A. Hensher John M. Rose (2010) Willingness to pay for travel time reliability in passenger transport: A review and some new empirical evidence.

Zografos, K.G., Androutsopoulos K.N., Nelson J.D., (2010) Indentifying Travelers' Information needs and services for an integrated international real time journey planning system. 13th International IEEE Annual Conference on Intelligent Transportation Systems 